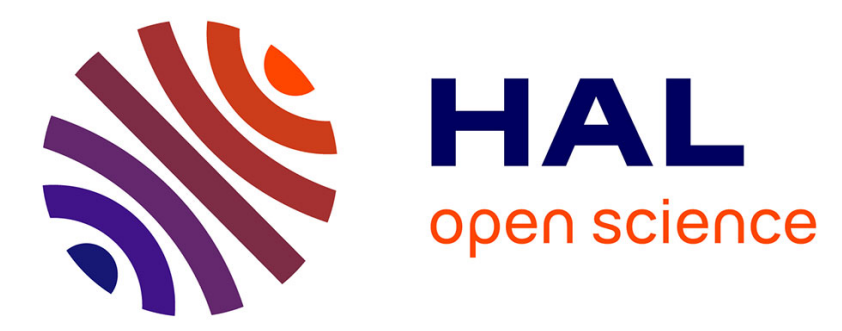

\title{
No answer to the lack of specificity: mouse monoclonal antibody targeting the angiotensin II type 1 receptor AT1 fails to recognize its target
}

Marie-Lynda Bouressam, Isabelle Lartaud, François Dupuis, Sandra Lecat

\section{- To cite this version:}

Marie-Lynda Bouressam, Isabelle Lartaud, François Dupuis, Sandra Lecat. No answer to the lack of specificity: mouse monoclonal antibody targeting the angiotensin II type 1 receptor AT1 fails to recognize its target. Naunyn-Schmiedeberg's Archives of Pharmacology, 2018, 391 (8), pp.883-889. $10.1007 / \mathrm{s} 00210-018-1522-4$. hal-01816221

\section{HAL Id: hal-01816221 \\ https://hal.univ-lorraine.fr/hal-01816221}

Submitted on 15 Jun 2018

HAL is a multi-disciplinary open access archive for the deposit and dissemination of scientific research documents, whether they are published or not. The documents may come from teaching and research institutions in France or abroad, or from public or private research centers.
L'archive ouverte pluridisciplinaire HAL, est destinée au dépôt et à la diffusion de documents scientifiques de niveau recherche, publiés ou non, émanant des établissements d'enseignement et de recherche français ou étrangers, des laboratoires publics ou privés. 
Rapid Communication

2 Naunyn-Schmiedeberg's Archives of Pharmacology

3

4 NO ANSWER TO THE LACK OF SPECIFICITY: Mouse monoclonal antibody targeting

5 the angiotensin II type 1 receptor $\mathrm{AT}_{1}$ fails to recognize its target.

6

7 Marie-Lynda BOURESSAM, ${ }^{1}$ MSc; Isabelle LARTAUD, ${ }^{1}$ PharmD, PhD; François

8 DUPUIS, ${ }^{1}$ PharmD, PhD ; Sandra LECAT, ${ }^{2} \mathrm{PhD}$

$9 \quad$ 1: Université de Lorraine, CITHEFOR, F-54000 Nancy, France

10 2: BSC UMR7242 "GPCRs, pain and inflammation" team, CNRS, Université de Strasbourg

11 Labex Medalis, 67412 Illkirch, France

12

13 Address for correspondence :

14 Dr Sandra LECAT

15 Institut de recherche de l'École Supérieure de Biotechnologie de Strasbourg:

16 Biotechnologie et Signalisation Cellulaire, UMR7242

17 Phone: (33)3-68-85-47-38

18 Email: lecat@unistra.fr

19

20 Running title: Another non-specific $\mathrm{AT}_{1}$ receptor mouse monoclonal antibody

21 Number of references: 24

22 Number of figures: 2

23 
5

\section{ABSTRACT}

Purpose. Numerous antibodies targeting G protein-coupled receptors, GPCRs, have been described as non-specific among them polyclonal antibodies against angiotensin II type 1 receptor $\left(A T_{1}\right)$. We have tested the newly developed $A T_{1}$ receptor mouse monoclonal antibody for its specificity.

Methods. Human Embryonic Kidney HEK293 cells, which do not endogenously express $\mathrm{AT}_{1}$ receptor, were transfected in order to overexpress a fluorescently labelled EGFP-tagged human $\mathrm{AT}_{1}$ receptor. Western blot and immunofluorescence assays were performed to test the specificity of the Santa Cruz monoclonal antibody sc- 57036 . These results were compared to the ones obtained with the polyclonal sc-1173 anti$\mathrm{AT}_{1}$ receptor antibodies that have already been described as non-specific.

Results. While the positive controls using GFP antibodies detected the EGFP-tagged $\mathrm{AT}_{1}$ receptor, both polyclonal and monoclonal anti-AT $\mathrm{T}_{1}$ receptor antibodies failed to specifically recognize the corresponding band by western blot, as similar bands were revealed in either transfected or non-transfected cells. It also failed to detect $A T_{1}$ receptor in immunofluorescence experiments.

Conclusion. The lack of target recognition of the monoclonal $\mathrm{AT}_{1}$ receptor antibody in our experimental conditions suggests that this antibody could give misleading results such as misidentification of the protein. To our knowledge, no specific antibodies targeting $\mathrm{AT}_{1}$ receptors have been developed so far and the field is thus in need of new technical developments.

Key words: G protein-coupled receptors - Angiotensin II type 1 receptor -antibody specificity 


\section{INTRODUCTION}

49 G protein-coupled receptors (GPCR) antibodies raise a lot of questions concerning offtarget detections (Michel et al. 2009). Numerous publications criticize the nonspecificity of different GPCR antibodies: histamine H4-receptors (Beermann et al. 2012) ; P2Y6 receptors (Yu and Hill 2013) ; cannabinoid receptors (Cécyre et al. 2014) ; dopamine receptors (Bodei et al. 2009).

Polyclonal antibodies targeting both angiotensin II (AnglI) receptors type 1 (AT $)$ and type $2\left(\mathrm{AT}_{2}\right)$ have been described as non-specific (Benicky et al. 2012; Herrera et al. 2013; Hafko et al. 2013). Despite these findings, antibodies directed against $A T_{1}$ receptors are still widely used in the literature with more than twenty publications in 2017 using the Santa Cruz aspecific sc-1173 polyclonal antibodies (Chao et al. 2017; Young et al. 2017; Liu et al. 2017) and already five publications in 2018 (Ahad et al. 2018; Ishikane et al. 2018; Rizzetti et al. 2018; Zhao et al. 2018; Ribeiro et al. 2018). In these papers, authors assume that they proved the specificity of these antibodies. However, in most cases, the control consisted of using the blocking peptide provided by the supplier to highlight the disappearance of the detected bands (Oestreicher et al. 2006). This type of experiment proves that the antibodies recognize the peptide used for immunization, however it is not sufficient to confirm that they recognize the targeted full-length protein. To overcome this issue, companies have developed monoclonal anti-AT 1 receptor antibodies presented as more specific.

In the present work, we evaluated the specificity of the Santa Cruz sc-57036 monoclonal anti-AT 1 receptor antibody.

Human Embryonic Kidney (HEK293) cells, that lacks endogenous $A T_{1}$ receptor expression, were transfected with a plasmid containing the human $\mathrm{AT}_{1}$ receptor tagged at its extracellular N-terminus with the enhanced green fluorescent protein (EGFP- 
73 AT 1 ). First, we assessed the robustness of our model by verifying the functionality of 74 the fluorescent receptor and its localization. Second, we tested the specificity of the 75 monoclonal sc-57036 antibody by Western blot and immunofluorescence. We 76 compared our data to the ones obtained using the polyclonal sc-1173 antibodies that 77 have already been described as non-specific. Our results indicate that the Santa Cruz 78 anti-AT 1 receptor monoclonal antibody sc-57036 does not label human $\mathrm{AT}_{1}$ receptor. 79 Moreover we confirmed the aspecificity of the polyclonal sc-1173 antibodies. 
MATERIALS AND METHODS

\section{Cell culture and transfection}

HEK 293 (Human Embryonic Kidney) cells were cultured to 80\% confluence in T-75$\mathrm{cm}^{2}$ flasks in MEM with Earle's salt supplemented with $10 \%$ fetal calf serum, $2 \mathrm{mM}$ glutamine and $1 \%$ antibiotics (penicillin/streptomycin) and re-plated twice a week. The expression vector pIRES (Clontech) encoding for the fluorescent EGFP-human $A_{1}$ receptor was a gift from Prof Haiech and Prof Kilhoffer (University of Strasbourg) and PCBIS UMS3286 CNRS-University of Strasbourg.

Cells stably expressing human EGFP-AT 1 receptors were, in addition, cultured with $600 \mu \mathrm{g} / \mathrm{ml} \mathrm{G} 418$ (Invitrogen)

\section{$\underline{\text { Antibodies }}$}

EGFP was detected with mouse monoclonal anti-GFP (A11120 Life technologies) and goat polyclonal anti-GFP directly coupled to Horse Radish Peroxidase HRP (AB6663, ABCAM). Tested antibodies against $A T_{1}$ receptors were the anti-AT 1 N-10 (Santa Cruz sc-1173 batch number C2415) and the anti-AT 1 TONI-1 (Santa Cruz sc-57036 batch number 12111$)$. The anti-AT $1 \mathrm{~N}-10$ is a rabbit polyclonal IgG with an epitope mapping within the $\mathrm{N}$-terminal extracellular domain of $A T_{1}$ receptor of human origin. It has just been discontinued. The anti-AT $\mathrm{T}_{1} \mathrm{TONI}^{-1}$ is a mouse monoclonal antibody raised against a GST fusion protein corresponding to amino acids 297-356 of AT 1 receptor of human origin. Both antibodies are recommended by the manufacturer for detection of $\mathrm{AT}_{1}$ receptor of mouse, rat and human origin by Western blot, immunoprecipitation, immunofluorescence and ELISA. 


\section{Calcium mobilization assay}

106 Cells were cultured for three days in T10, then loaded with $2.5 \mu \mathrm{M}$ Fluo-4 AM 107 (Molecular Probes) for $1 \mathrm{~h}$. Cells were rinsed in PBS, collected in PBS-5mM EDTA and

108 suspended in $9 \mathrm{~mL}$ Hepes-BSA buffer (10 mM HEPES pH 7.4, $137.5 \mathrm{mM} \mathrm{NaCl}, 1.25$ $\mathrm{mM} \mathrm{MgCl} 2,1.25 \mathrm{mM} \mathrm{CaCl}$, $6 \mathrm{mM} \mathrm{KCl}, 5.6 \mathrm{mM}$ glucose, $0.4 \mathrm{mM} \mathrm{NaH} 2 \mathrm{PO} 4,0,1 \%$ Bovine Serum Albumine). Cells were loaded in 96-well plates (Greiner 655090, 100 $\mu \mathrm{L} /$ well) and centrifuged for $3 \mathrm{~min}$ at $800 \mathrm{rpm}$. Angll-evoked increases in intracellular calcium were recorded over time using a Flexstation III (Molecular Devices, Sunnyvale, CA, USA) ( $3 \mathrm{sec}$ intervals over $220 \mathrm{sec}$ ) at $37^{\circ} \mathrm{C}$ through fluorescence emission at 520 $\mathrm{nm}$ (excitation at $485 \mathrm{~nm}$ ). Peak response amplitudes were normalized to basal fluorescence levels. For each concentration of the agonist, we determined the maximal value of the increase in calcium concentration in order to build concentration response curves to Angll.

\section{Cell surface expression of the fluorescent EGFP-AT1 receptor}

Cells were cultured for two days in T10, then rinsed in PBS, collected in PBS-5mM EDTA. Immunolabelling of EGFP-AT 1 receptors expressed at the cell surface was done on intact cells (approximately 1 million cells) pre-incubated in $1 \mathrm{~mL} \mathrm{PBS}-1 \%$ BSA on ice for 1 hour, then labelled using mouse monoclonal anti-GFP (A11120 Life technologies 1/100 dilution in PBS 1\% BSA) for 30 min on ice and secondary labelling done using a R-phycoerythrin-conjugated AffiniPure $F\left(a b^{\prime}\right) 2$ fragment goat anti-mouse IgG (1/100 dilution). EGFP fluorescence and phycoerythrin (PE) staining were detected by flow cytometric analysis (20,000 cells per sample) on a cytometer (FACSCalibur, Becton-Dickinson). 
131 Cells were cultured for two days in 6-well plates. Cell lysates were performed in 250 $132 \mu \mathrm{L}$ RIPA buffer (20 mM de Tris- $\mathrm{HCl} \mathrm{pH} 7.4,150 \mathrm{mM}$ de $\mathrm{NaCl}, 1 \%$ de NP40, 0.25\% de 133 Na-deoxycholate, $0.1 \%$ SDS, Complete protease inhibitor EDTA-free (Roche) 134 according to Lecat et al. (2015). In order to concentrate the receptors, in some 135 experiments, cell lysates underwent immunoprecipitation. Briefly $450 \mu \mathrm{g}$ of proteins 136 were exposed to mouse monoclonal anti-GFP (A11120 Life technologies, 1:100) 137 overnight on a wheel at $4^{\circ} \mathrm{C}$ before coupling to Protein $\mathrm{A}$ sepharose $4 \mathrm{~B}$ (Life 138 technologies) for 2 hours at $4^{\circ} \mathrm{C}$ the following day. Protein A / antibodies complexes 139 were washed 3 times in $1 \mathrm{~mL}$ RIPA buffer by successive centrifugations at $2000 \mathrm{rpm}$ 140 for $1 \mathrm{~min}$ at $4^{\circ} \mathrm{C}$ before being suspended in $2 \mathrm{X}$ Laemmli buffer.

141 Proteins were not heated and directly separated on $10 \%$ acrylamide SDS-PAGE gel 142 electrophoresis. Proteins were then transferred onto PVDF polyvinyl difluoride 143 membranes for 2 hours and western blotting was performed according to Lecat et al. 144 (2015). Concentrations of antibodies were: polyclonal rabbit anti-AT 1 receptor (Santa 145 Cruz sc-1173) 1:500 and monoclonal mouse anti-AT 1 receptor (Santa Cruz sc-57036) 146 1:500. PVDF membranes were washed in acid buffer for desorbing the antibodies and 147 reprobed with goat polyclonal anti-GFP directly coupled to Horse Radish Peroxidase HRP (AB6663, ABCAM) 1:25 0000. Secondary anti-rabbit HRP and anti-mouse HRP 149 antibodies were used at a dilution of $1: 10000$ and 1:5000 respectively (Immuno 150 Research Laboratories).

\section{Immunofluorescence}

153 Cells were cultured for 24 hours in 24-well plates on 12-mm in diameter coverslips 154 coated with rat type I collagen. Cells were fixed in PBS containing 4\% 
155 paraformaldehyde, rinsed twice with PBS and exposed $15 \mathrm{~min}$ to $50 \mathrm{mM}$ ammonium 156 chloride in order to quench remaining paraformaldehyde fluorescence. Cells were then 157 rinsed three additional times in PBS. Cells exposed to the monoclonal sc-57036 158 antibody were permeabilized $3 \mathrm{~min}$ in PBS containing $0,1 \%$ Triton $\mathrm{X}-100$. 159 Immunolabelling was performed in PBS-0.2\% BSA with either polyclonal anti-AT1 160 receptor (sc-1173, 1:50), monoclonal anti-AT 1 receptor (sc-57036, 1:50) or monoclonal 161 anti-GFP (A11120, 1:100). Cells were washed 3 times in PBS-0.2\% BSA and 162 incubated further with either secondary goat anti-rabbit or goat anti-mouse antibodies 163 coupled to Alexa 594 (Invitrogen ;1:200). After further washes in PBS, coverslips were 164 mounted onto slides using an anti-fading agent (Mowiol; Calbiochem). Image 165 acquisition was performed with a fluorescent microscope LEICA (motorized 166 microscope Leica DM5500B together with cold-camera Leica CTR 6000). Figures were 167 created with FigureJ. 


\section{RESULTS}

169

170

171

172

173

174

175

176

Validation of the experimental model: in transfected cells, fluorescently-labelled $A T_{1}$ receptors are functional and localized at the plasma membrane

In cells expressing the fluorescently labelled EGFP-AT 1 , the receptor is fused at its extracellular $\mathrm{N}$-terminus with the fluorophore (Fig. 1A). We verified that the receptor was active in these cells by measuring calcium responses to Angll. While the parental HEK293 cells did not respond to the agonist, showing that the receptor is not endogenously expressed, EGFP-AT 1 cells gave a nice Angll dose-response with an EC50 around $2.10^{-8} \mathrm{~mol} / \mathrm{L}$ Angll (Fig. 1B). Using fluorescence cell sorting analysis, we have controlled that all the cells were expressing the fluorescent receptor (as detected by the peak of EGFP fluorescence as compared to non-transfected cells, Fig. 1C, left) and that the receptor was properly localized at the cell surface (as detected by surface labelling with anti-GFP antibodies followed by red fluorescent secondary antibody labelling, Fig. 1C, right).

\section{Polyclonal and monoclonal anti-AT 1 antibodies detected bands in Western blot} whether the receptor was expressed or not

The expected size of the fusion protein, EGFP-AT 1 receptor, estimated from the aminoacid sequence, is $73 \mathrm{kDa}$. The estimation does not take into account post-translational modifications such as $N$-glycosylation. In Western blot of total cell extracts $(40 \mu \mathrm{g}$ of proteins), both monoclonal sc-57036 and polyclonal sc-1173 antibodies detected bands whether the fluorescently labelled receptor was expressed or not (Fig. 2A; total lysates). Reprobing of the membrane with monoclonal anti-GFP antibody specifically revealed a major band in HEK-EGFP-AT 1 transfected cells (but not in parental cells) around $90 \mathrm{kDa}$ corresponding to the tagged-receptor. A smaller band around $40 \mathrm{kDa}$ 
193 is also detected with the anti-GFP, that could correspond to degraded receptors mainly

194

195 with the EGFP tag left.

In a second attempt to detect the receptors with anti-AT 1 receptor antibodies, we performed immunoprecipitations of $450 \mu \mathrm{g}$ of protein extracts with monoclonal antiGFP antibody in order to concentrate the receptors prior to Western blotting. Again, polyclonal sc-1173 and monoclonal sc-57036 revealed unspecific bands in both nontransfected and HEK-EGFP-AT 1 transfected cell lysates (Fig. 2A; anti-GFPimmunoprecipitated lysates). Reprobing the membrane with anti-GFP-HRP antibody specifically revealed the EGFP-AT 1 receptor bands only in cells expressing the fluorescently-labelled receptor (Fig. 2A; immunoprecipitated lysates).

\section{Both anti-AT, receptor antibodies failed to recognize the receptor by immunofluorescence}

Next, we tested the antibodies in immunofluorescence labelling experiments on EGFPtagged $\mathrm{AT}_{1}$ receptor expressing cells. Cells cultured on coverslips were labelled either with anti-GFP or anti-AT 1 receptors antibodies, followed by a red fluorescent secondary antibody detection. Using epifluorescence microscopy, images collected in the green channel to directly visualize the fluorescence of EGFP showed a localization of the receptor principally at the cell plasma membrane and in some intracellular perinuclear compartments (Fig. 2B-a, 2B-d, 2B-g).

Staining with the monoclonal GFP antibody on non-permeabilized cells revealed only the plasma membrane localization of the receptor (Fig. 2B-b).

When using the polyclonal anti-A $\mathrm{T}_{1}$ receptor antibodies, no plasma membrane staining was detected (Fig. 2B-e). We obtained similar results with the monoclonal anti-AT 1 receptor antibody. For this antibody, we performed permeabilization of the cells due to 
218 the localization of the epitope in the C-terminus tail of the receptor. While, in the green

219 channel, the receptor could still be detected by the direct fluorescence of EGFP (Fig.

$2202 \mathrm{~B}-g$ ), no specific labelling with the monoclonal anti-AT 1 receptor antibody in the red

221 channel (Fig. 2B-h) and no colocalization in the overlay channel were visible (Fig. 2B222 i).

223 Therefore, in accordance with our results obtained by Western blot, monoclonal and 224 polyclonal anti-AT 1 receptors antibodies also failed to recognize $\mathrm{AT}_{1}$ receptors by 225 immunofluorescence. 


\section{DISCUSSION}

227 Here we bring the first evidence of the lack of specificity of the Santa Cruz monoclonal anti-AT 1 antibody sc-57036 as it failed to specifically recognize the $\mathrm{AT}_{1}$ receptor. In the present work we used an heterologous model of human $\mathrm{AT}_{1}$ receptors expression in which the receptor is tagged with the EGFP fluorescent protein at its extracellular Nterminal domain. Before assessing the specificity of anti-AT 1 receptor antibodies, we

232 first evaluated the robustness of our model. HEK cells stably expressed the EGFP-AT 1 receptors homogeneously in the cell population. The receptors were properly localized at the cell surface and functional.

We confirm here the aspecificity of the $\mathrm{AT}_{1}$ receptor polyclonal antibodies sc-1173, since bands were revealed by Western blot in all lysates whether $\mathrm{AT}_{1}$ receptor was present or not. We obtained the same results with the $A T_{1}$ receptor monoclonal antibody sc-57036. Moreover, both $\mathrm{AT}_{1}$ receptor antibodies failed to recognize the receptor in immunofluorescence labelling assays. To our knowledge, this is the first report questioning the specificity of Santa Cruz monoclonal $\mathrm{AT}_{1}$ receptor antibody sc57036. Already used in 10 publications (including three in 2017 and one in 2018) (Filice et al. 2017; Yim et al. 2017; Ferrão et al. 2017; Sinphitukkul et al. 2018), this antibody that lacks specificity could lead to false positive staining on tissue or primary cell culture and therefore misinterpretations.

247 Concerning the sc-1173 antibodies, our results are in accordance with the ones 248 obtained by Benicky et al. (2012). They tested 6 commercially available anti-AT 1 249 receptor antibodies (including sc-1173) by Western blot and immunofluorescence. All 250 of them failed to recognize specifically the receptor. First, they assessed the 
251 robustness of their models ( $\mathrm{AT}_{1 \mathrm{~A}}$ knock-out mice and rat hypothalamic $4 \mathrm{~B}$ cells) by 252 verifying the lack of expression of $A T_{1}$ receptor in both models using radioligand 253 binding assays. Second, they compared the immunoreactivity of the antibodies in 254 knock-out tissues and in cells transfected or not with $\mathrm{AT}_{1}$ receptor. The six antibodies 255 (including sc-1173) displayed very different pattern and intensity of immunoreactivity. 256 But all tested antibodies gave signals in tissues from $\mathrm{AT}_{1 \mathrm{~A}}$ knock-out mice and non257 transfected 4B cells. Despite this first report of aspecificity, the sc-1173 antibodies 258 were still widely used in the literature up to now (Rizzetti et al. 2018; Zhao et al. 2018; 259 Ribeiro et al. 2018) and it has just been discontinued.

261 Since antibodies directed against GPCR have been widely criticized for their lack of 262 specificity, a correct validation of the used antibodies should be provided by the 263 authors and requested by journals editors. Use of blocking peptide is a weak proof of specificity and using tagged receptors is a more reliable alternative method. Authors could also rely on one of the four criteria proposed by Michel et al. (2009) to demonstrate specific immunolabelling of receptors in tissues: a) disappearance of 267 staining in knock-out animals of the target receptor, b) reduction of staining upon 268 knock-down approaches such as siRNA treatment, c) selectivity of staining in immunoblots or immunocytochemistry for the target receptor vs related subtypes when expressed in the same cell line and/or d) antibodies raised against multiple distinct 271 epitopes of a receptor yielding very similar staining patterns.

273 Given the issues concerning GPCR antibody specificity, the use of new tools to detect 274 these membrane proteins is thus essential. Single-domain antibody (or nanobody) 275 arouse great interest in the scientific community. Indeed, they show a promising 
276 potential for research or therapeutic (Rasmussen et al. 2011; Maussang et al. 2013).

277 They have smaller sizes (around $15 \mathrm{kDa}$ vs $150 \mathrm{kDa}$ for a classical antibody), they can 278 be expressed intracellularly, they can display higher affinity and specificity and they 279 have lower cost of production. Hence, the emergence of nanobodies is likely to replace 280 actual existing polyclonal and monoclonal antibodies to ensure a reliable detection of 281 GPCR proteins.

282 In conclusion, we demonstrate here that the monoclonal $\mathrm{AT}_{1}$ receptor antibody sc28357036 should be added to the long list of non-specific antibodies targeting GPCRs. 


\section{ABBREVIATIONS}

285 Angll: angiotensin II

286 AT 1 : angiotensin II type 1 receptor

287 AT 2 : angiotensin II type 2 receptor

288 EGFP: enhanced green fluorescent protein

289 HEK293: human embryonic kidney cell

290 GPCR: G protein-coupled receptor

291 PE: phycoerythrin

292 PBS: phosphate buffered saline 


\section{AUTHORS CONTRIBUTION}

294 SL conceived and designed the experiments. MLB and SL conducted the experiments.

295 MLB, IL, FD, SL analyzed data and wrote the manuscript. All the authors read and 296 approved the manuscript. 


\section{REFERENCES}

Ahad A, Raish M, Al-Jenoobi FI, Al-Mohizea AM (2018) Sorbitane Monostearate and Cholesterol based Niosomes for Oral Delivery of Telmisartan. Curr Drug Deliv 15:260-266. doi: 10.2174/1567201814666170518131934

Beermann S, Seifert R, Neumann D (2012) Commercially available antibodies against human and murine histamine $\mathrm{H}$-receptor lack specificity. Naunyn Schmiedebergs Arch Pharmacol 385:125-135. doi: 10.1007/s00210-011-0700-4

Benicky J, Hafko R, Sanchez-Lemus E, et al (2012) Six commercially available angiotensin II AT1 receptor antibodies are non-specific. Cell Mol Neurobiol 32:13531365. doi: 10.1007/s10571-012-9862-y

Bodei S, Arrighi N, Spano P, Sigala S (2009) Should we be cautious on the use of Arch Pharmacol 379:413-415. doi: 10.1007/s00210-008-0384-6

Cécyre B, Thomas S, Ptito M, et al (2014) Evaluation of the specificity of antibodies raised against cannabinoid receptor type 2 in the mouse retina. Naunyn Schmiedebergs Arch Pharmacol 387:175-184. doi: 10.1007/s00210-013-0930-8

Chao Y, Zhu L, Qu X, et al (2017) Inhibition of angiotension II type 1 receptor reduced human endothelial inflammation induced by low shear stress. Exp Cell Res 360:94-104. doi: 10.1016/j.yexcr.2017.08.030

Ferrão FM, Cardoso LHD, Drummond HA, et al (2017) Luminal ANG II is internalized as a complex with AT1R/AT2R heterodimers to target endoplasmic reticulum in LLCPK1cells. Am J Physiol Renal Physiol 313:F440-F449. doi: 10.1152/ajprenal.00261.2016

Filice M, Amelio D, Garofalo F, et al (2017) Angiotensin II dependent cardiac remodeling in the eel Anguilla anguilla involves the NOS/NO system. Nitric Oxide Biol Chem 65:50-59. doi: 10.1016/j.niox.2017.02.007

Hafko R, Villapol S, Nostramo R, et al (2013) Commercially Available Angiotensin II At2 Receptor Antibodies Are Nonspecific. PLoS ONE 8:. doi: 10.1371/journal.pone.0069234

Herrera M, Sparks MA, Alfonso-Pecchio AR, et al (2013) Lack of specificity of commercial antibodies leads to misidentification of angiotensin type 1 receptor protein. Hypertens Dallas Tex 1979 61:253-258. doi: 10.1161/HYPERTENSIONAHA.112.203679

Ishikane S, Hosoda H, Nojiri T, et al (2018) Angiotensin II promotes pulmonary metastasis of melanoma through the activation of adhesion molecules in vascular endothelial cells. Biochem Pharmacol. doi: 10.1016/j.bcp.2018.04.012

Lecat S, Belemnaba L, Galzi J-L, Bucher B (2015) Neuropeptide Y receptor mediates activation of ERK1/2 via transactivation of the IGF receptor. Cell Signal 27:12971304. doi: 10.1016/j.cellsig.2015.03.016

Liu C-H, Gong Z, Liang Z-L, et al (2017) Arrestin-biased AT1R agonism induces acute catecholamine secretion through TRPC3 coupling. Nat Commun 8:14335. doi: 10.1038/ncomms14335

Maussang D, Mujić-Delić A, Descamps FJ, et al (2013) Llama-derived single variable 
domains (nanobodies) directed against chemokine receptor CXCR7 reduce head and neck cancer cell growth in vivo. J Biol Chem 288:29562-29572. doi: 10.1074/jbc.M113.498436

Michel MC, Wieland T, Tsujimoto G (2009) How reliable are G-protein-coupled receptor antibodies? Naunyn Schmiedebergs Arch Pharmacol 379:385-388. doi: 10.1007/s00210-009-0395-y

Oestreicher EM, Guo C, Seely EW, et al (2006) Estradiol increases proteinuria and angiotensin II type 1 receptor in kidneys of rats receiving L-NAME and angiotensin II. Kidney Int 70:1759-1768. doi: 10.1038/sj.ki.5001897

Rasmussen SGF, Choi HJ, Fung JJ, et al (2011) Structure of a nanobody-stabilized active state of the $\beta 2$ adrenoceptor. Nature 469:175-181. doi: 10.1038/nature09648

Ribeiro VS, Cabral EV, Vieira LD, et al (2018) Perinatal a-tocopherol overload programs alterations in kidney development and renal angiotensin II signaling pathways at birth and at juvenile age: Mechanisms underlying the development of elevated blood pressure. Biochim Biophys Acta. doi: 10.1016/j.bbadis.2018.04.007

Rizzetti DA, da Silva TM, Escobar AG, et al (2018) Mercury-induced vascular dysfunction is mediated by angiotensin II AT-1 receptor upregulation. Environ Res 162:287-296. doi: 10.1016/j.envres.2018.01.026

Sinphitukkul K, Manotham K, Eiam-Ong S, Eiam-Ong S (2018) Nongenomic action of aldosterone on colocalization of angiotensin II type 1 and type 2 receptors in rat kidney. J Histotechnol 0:1-8. doi: 10.1080/01478885.2018.1438756

Yim HE, Yoo KH, Bae IS, Hong YS (2017) Early Treatment With Enalapril and Later Renal Injury in Programmed Obese Adult Rats. J Cell Physiol 232:447-455. doi: 10.1002/jcp.25444

Young BM, Nguyen E, Chedrawe MAJ, et al (2017) Differential Contribution of Transmembrane Domains IV, V, VI, and VII to Human Angiotensin II Type 1 Receptor Homomer Formation. J Biol Chem 292:3341-3350. doi: 10.1074/jbc.M116.750380

Yu W, Hill WG (2013) Lack of specificity shown by P2Y6 receptor antibodies. Naunyn Schmiedebergs Arch Pharmacol 386:885-891. doi: 10.1007/s00210-013-0894-8

Zhao Y, Zhu Q, Sun S, et al (2018) Renal transplantation increases angiotensin II receptor-mediated vascular contractility associated with changes of epigenetic mechanisms. Int J Mol Med 41:2375-2388. doi: 10.3892/ijmm.2018.3435 
A

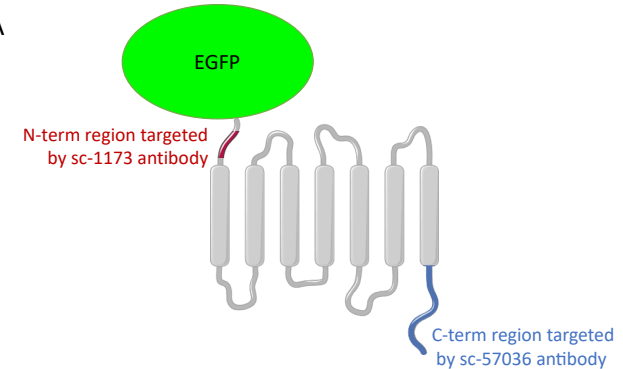

C

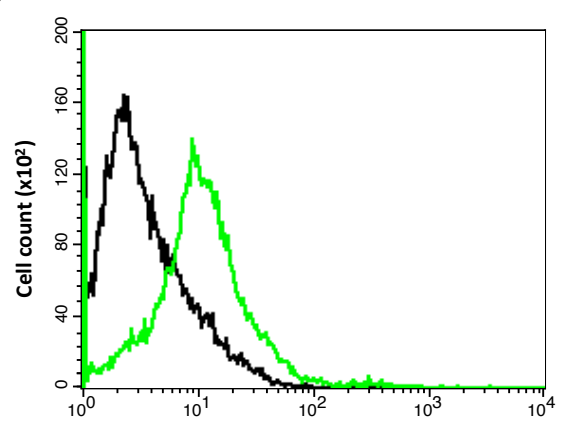

GFP
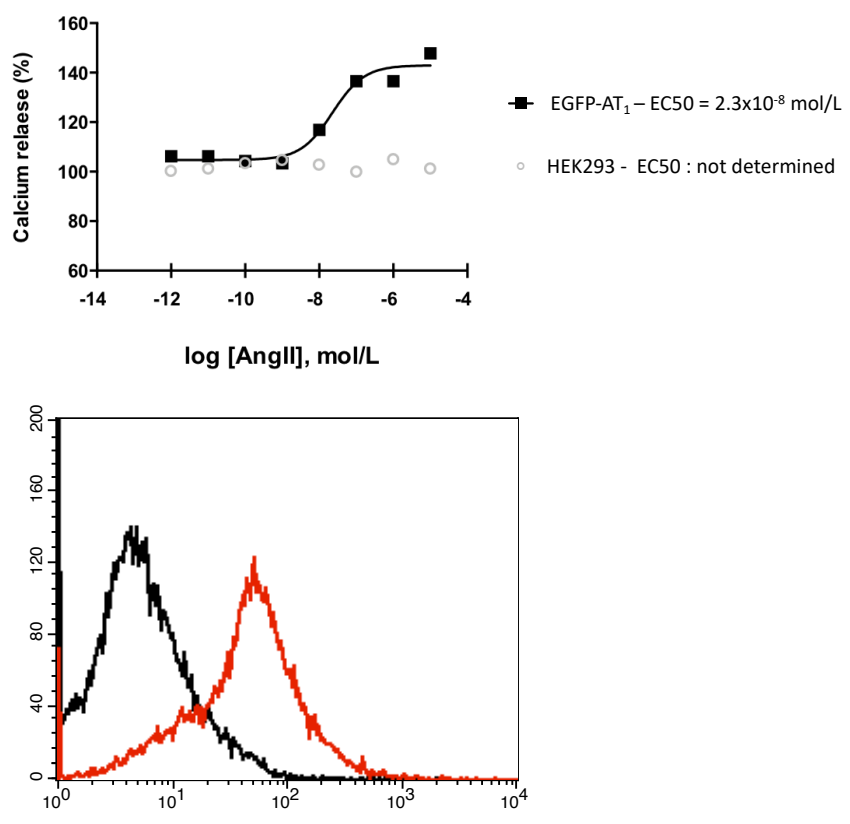

PE
376

Figure 1. In EGFP-AT 1 transfected cells, $\mathrm{AT}_{1}$ receptor is properly localized at the cell surface

A - Schematic view of the fusion protein EGFP-AT 1 receptor. The EGFP fluorophore is localized in the extracellular N-terminal part of the receptor. The sc-1173 polyclonal anti-AT $T_{1}$ receptor targets the short $\mathrm{N}$-terminal domain of the receptor while the epitope for the sc-57036 monoclonal anti-AT1 receptor encompassed the whole C-terminal tail of the receptor.

B - HEK293 and EGFP-AT 1 transfected cells were exposed to Angiotensin II (Angll ; $10^{-12}$ to $\left.10^{-4} \mathrm{~mol} / \mathrm{L}\right)$. Angll-evoked increases in intracellular calcium were recorded over time using a Flexstation III ( $3 \mathrm{sec}$ intervals over $220 \mathrm{sec}$ ) at $37^{\circ} \mathrm{C}$ through fluorescence emission at $520 \mathrm{~nm}$ (excitation at $485 \mathrm{~nm}$ ). Peak response amplitudes were normalized to basal fluorescence levels. Each point represents the maximal value at $520 \mathrm{~nm}$ for a given Angll concentration.

C - The cell population expressing the EGFP-AT 1 receptors was compared to non- 
391 transfected cells by fluorescence-activated cell sorting. Left panel: Histogram of cells 392 expressing the GFP fluorescence (green line: cells expressing stably the EGFP-AT 1 393 receptors, black line: non-transfected HEK293 cells). Right panel: Histogram of cells 394 labelled with phycoerythrin (PE): intact cells were stained with anti-GFP antibodies and 395 secondary phycoerythrin-labeled antibodies (PE). Fluorescence intensities of non396 transfected HEK cells (black line) and cells expressing stably the EGFP-AT 1 receptors 397 (red line). 
A
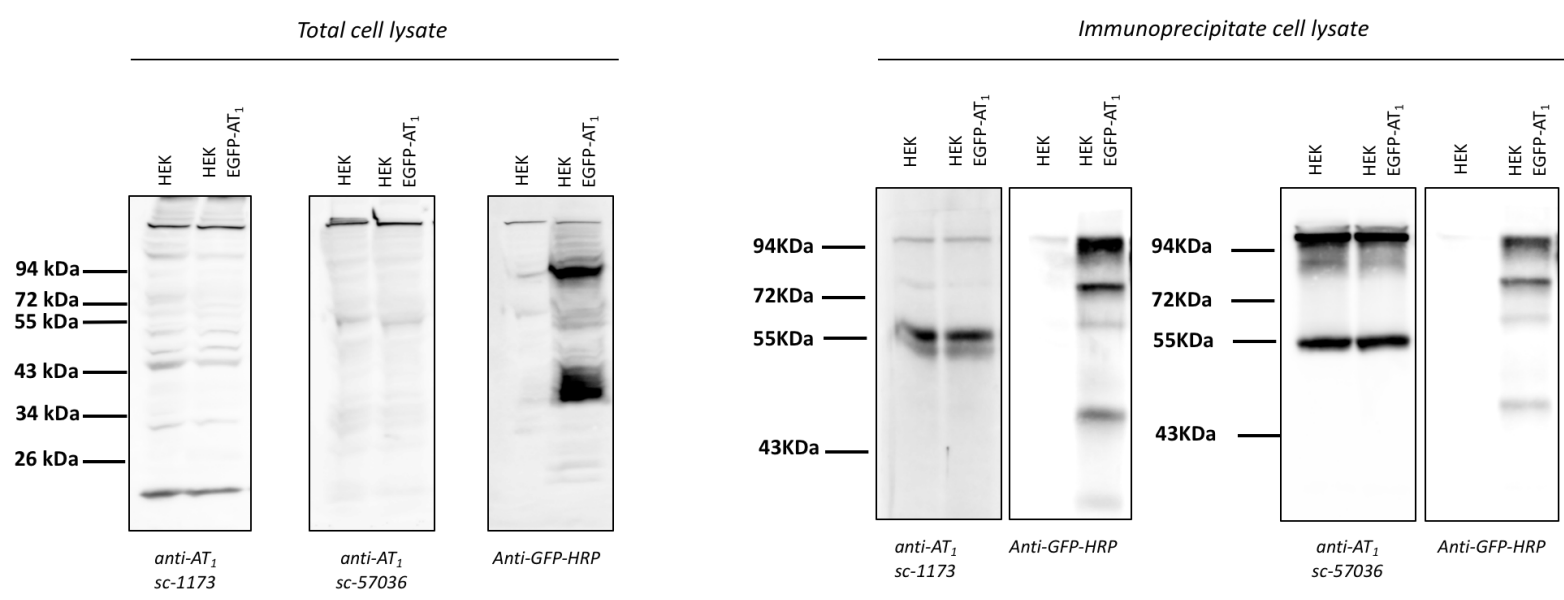

B

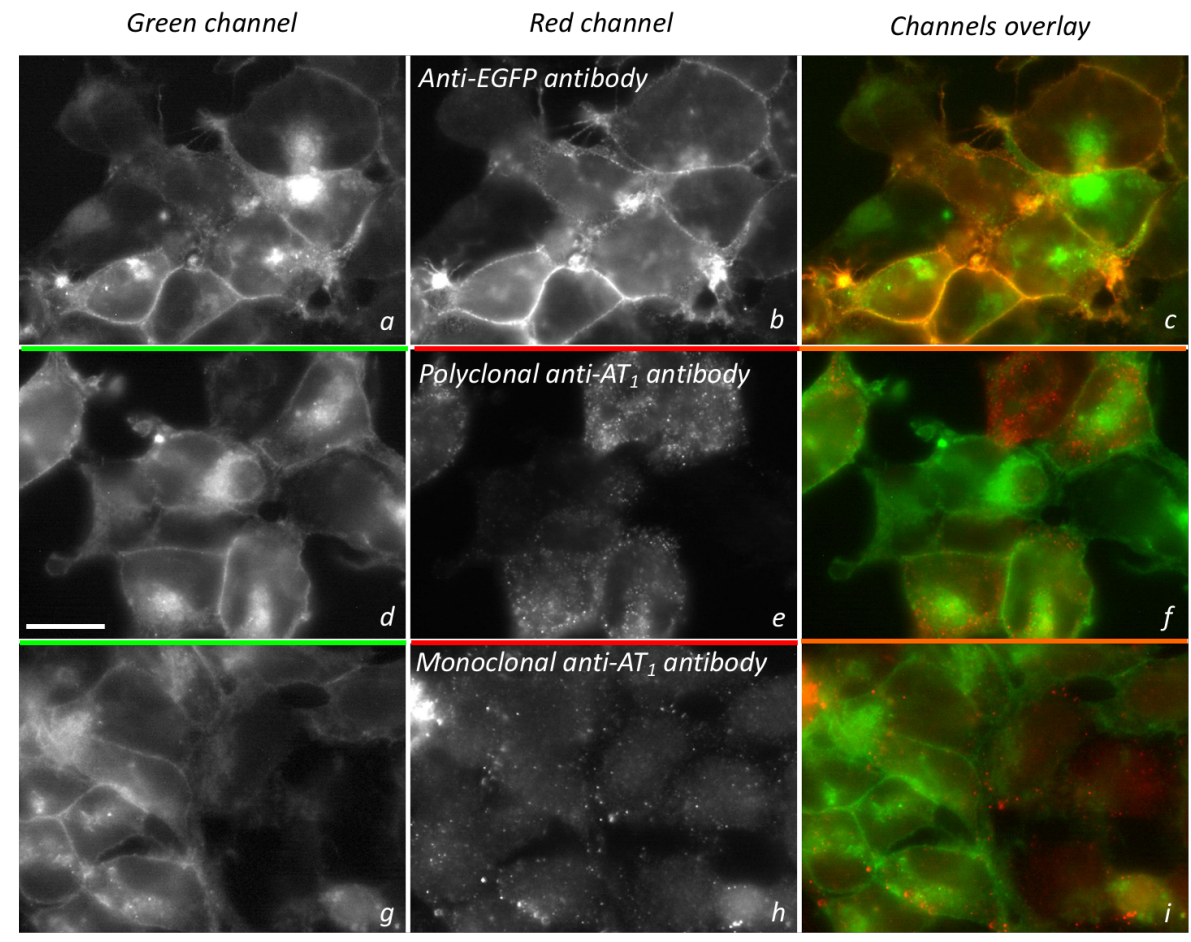

399 Figure 2. Monoclonal and polyclonal anti-AT 1 receptor antibodies failed to recognize EGFP-AT 1 receptor in both Western blot and immunofluorescence assays

402 A - Immunoblot of total cell lysates (left $-40 \mu \mathrm{g}$ of proteins) or of anti-GFP 403 immunoprecipitated material (right $-450 \mu \mathrm{g}$ of proteins) of non-transfected HEK293 404 cells and of cells expressing stably the EGFP-AT 1 receptors. Proteins were revealed 405 with either polyclonal anti-AT 1 sc-1173, monoclonal anti-AT 1 sc-57036 or anti-GFP- 
406 HRP antibodies. Anti-GFP antibody revealed bands only in cells expressing the EGFP-

$407 \mathrm{AT}_{1}$ receptor whereas sc-1173 and sc-57036 anti-AT ${ }_{1}$ antibodies revealed unspecific 408 bands whether the receptor had been transfected or not.

409 B - Antibodies immunolabelling on EGFP-tagged AT 1 cells. $(a, d, g)$ Images collected 410 in the green channel using epifluorescence microscopy showing the fluorescence of 411 the EGFP-tagged receptor which is localized principally at the cell plasma membrane 412 and in some perinuclear compartments. $(b, e, h)$ Images collected in the red channel, 413 stained with primary antibodies directed against GFP epitope in $b$, or $\mathrm{AT}_{1}$ receptor (e, 414 sc-1173, $h$, sc-57036) followed by a red secondary antibody. Plasma membrane 415 localization of the receptor and colocalization with the GFP signal (displayed in the 416 channel overlay) is only detected with the anti-GFP labelling ( $b$ and $c$ respectively), 417 whereas no plasma membrane signal ( $e$ and $h$ ) or colocalization ( $g$ and $i$ ) could be 418 detected when using anti-AT 1 antibodies. Scale bar is $10 \mu \mathrm{M}$. 